\title{
O sexo do futuro... um breve ensaio sobre a bissexualidade
}

Arnaldo Dominguez*

"Os melhores de sua espécie, são apenas sombras"

De W. Shakepeare, em "Sonho de uma noite de verão", por Oscar Wilde, Contos, Nova Fronteira, 1994.

Falar sobre a bissexualidade, como pretendo, implica em falar de três lugares, basicamente. O meu lugar de escuta analítica, o meu lugar de "Flâneur" que, segundo Benjamin. imprime suas próprias marcas nas coisas e o meu lugar de leitor, que pensa a partir dos pensadores.

Querer ir mais além, seria aspirar a uma verdade arrogante, e de inicio abro mão deste (des) propósito.

Falar de bissexualidade neste ensaio, significa também me questionar para compreender minha experiência clínica e assim saber o que estou ouvindo - quando os clientes em análise, que se auto-denominam "bissexuais" - enunciam nos discursos e apelos.

* Projeto: Etcetera e Tal... Núcleo de estudos das relações de gênero nas minorias sexuais. SBRASH - Sociedade Brasileira de Sexualidade Humana. 
Também não posso ter a pretensão de "dar conta" do tema, pois deverei me apoiar nos meus escassos conhecimentos e no máximo, numa dúzia de histórias, talvez um pouco mais.

Mas, porque não falar? Uma dúzia já e um número significativo como para pedir a palavra. Portanto, em nome deles, eu pergunto: $\mathrm{O}$ que quer, afinal, um bissexual?

Este individuo existe, de fato? Ou trata-se de um Homo ou de um Hetero, "confusos"?

No caso de existir (e creio que aqui, a resposta seja, de algum modo, afirmativa), deverá "definir-se" por um lado ou por outro? (Sendo esta uma dúvida freqüente e um pedido comum, na análise).

Nosso mundo tem andado dividido em "homos" e "heteros" (muito mais do que em homens e mulheres), no entanto, após certas publicações jornalísticas ou livros classificatórios a respeito dos quantos sexos existem (?) etc., muitos seres humanos encontram as primeiras palavras de um novo discurso que os nomeia. introduzindo-os na língua, da qual se julgavam excluídos.

Por outro lado, nós, os analistas, também somos obrigados a articular significantes neologísticos a nossos discursos interpretativos, e devemos tomar a precaução de não ficarmos no lugar do legislador que impõe a norma pré-estabelecida pelo estatuto da "moral -psicanalítica". Muito menos da moral religiosa.

Eu sei que a psicanálise não é uma religião, embora possa se assemelhar. É que temos, e não poderia ser de outro modo, um jargão particular, que algumas vezes não diz nada e outras, ao dizer, denuncia a própria crença. (A crença pessoal do analista, apesar dos cuidados éticos que toma, não deixa definitivamente de ser um sujeito falante, nascido no discurso da cultura-discurso este, dominante que pré-existe a seu ser). Em certas ocasiões receio que por detrás do hermenêutico discurso das epistemologias, oculta-se um desejo perverso de "saber tudo" e assim obter poder sobre o outro ao excluí-lo da possibilidade de compreensão, devendo submeter-se. necessáriamente, ao dito pelo amo, que fala.

Considero importante situá-los sobre como penso alguns conceito fundamentais da psicanálise, por exemplo: Ao referir-me ao estatuto do inconsciente, não estou descrevendo alguma "essência" deste inconsciente. Ao pensar no estatuto do desejo, idem.

Postulo aqui, a dimensão ética de tais considerações teóricas. Sem possibilidade topográfica, sem biologia. Quase que sem ciência. Mais do que ciência, ausência. Algo que não está em lugar nenhum. Quase não existe. Que aparece e desaparece no tempo de sua abertura. Mas que não vêem nem vai para lugar nenhum. Apenas aparece no sintoma (como por 
exemplo: no sintoma de toda sexualidade) ou na parapraxia. E nos tempos de ver, compreender e concluir, dos eventos analíticos.

Então, que ética será esta, diferente d'aquela inscrita nas páginas da moral? Será uma ética em prol da cultura? Sim e não!

Trata-se de uma ética diferente, cujo dever norteara o estatuto do sujeito. Trata-se sim, do bem e do mal, mas a respeito do sujeito, que entrará no social pela porta dos discursos, o que torna esta ética (de ethos: indivíduo), POLÍTICA (de polis: a cidade. O cidadão e seus direitos).

Sei que continuamos de algum modo, no sistema do Senhor e Escravo e que, portanto, os discursos de entrada no espaço público, possuem várias portas de acesso. Mas poderia simplificá-las em três básicas:

A porta da frente, a lateral e a dos fundos, ou, como é dito, a dos cidadãos de primeira, segunda e terceira categorias, respectivamente.

Há outras, muitas combinações de outras portas por detrás das quais ocultam-se as categorias dos excluídos da língua.

Os que não podem se nomear pois não ousam dizer seus nomes (e mesmo que os dissessem, ninguém parece estar interessado em ouví-los). Ao contrário, quiçá para dominá-los, como corresponde ao "senhor", são rebatizados para continuarem escravizados às linguagens epistemológicas.

Aprisionados ao "não-dito" (ou ao "mal-dito"), que ética poderiam construir que não fosse a clandestina, marginal (à lingua), perversa, nebulosa, anônima? E tudo mais que quisserem.

Me convenço mais a mais a cada dia, que a entrada do excluído (dito perverso) às semióticas públicas, acarreta, concomitantemente a possibilidade de ser castrado, pelo próprio efeito do discurso.

Não que os falantes deixem de ser perversos, sabemos que há muitos bem próximos do sagrado que o são, embora falem em nome de Deus; ou até por isso. Deus garante o que falo. Meu pai garante. Freud explica.

Refiro-me ao ingresso como sujeito do desejo, capaz de construir para "si mesmo". uma ética. A Ética da liberdade de ir e vir (de transitar) e de poder escolher, desalienado, o modo mais apropriado (mais próprio) de ser e de estar no mundo, como diz Mariana Friedrich.

Ao tornar-se público, mediante o recurso denominado "visibilidadè - ou -assumir-se" (assinar embaixo, responsabilizando-se pela obra, sempre sujeita a críticas, deboches e aplausos), ganha o direito humano por excelência: o da vida. Pagando o preço que isto custa, que é a perda do "gozo do nirvana". Mas adquirindo (apenas) a dor e a delícia do seu Gozo-diferente. 
Fazendo uma retranscrição de Freud, a respeito do "mal estar da civilização", por Nelson Brissac Peixoto, em: A sedução da barbárie: o marxismo na modernidade (Ed. Prasiliense, 1982), encontramos que "Freud sistematizaria a idéia, comum à época, de que o 'princípio do prazer' só existe para aqueles que assumem riscos contra a ordem. A cultura, como instrumento e expressão sublimada da civilização a do progresso, se ergue portanto, sobre o cadáver do desejo e do gozo. É fruto da repressão. Daí a vontade de destruição da cultura e da ordem, a recusa atual de adiar a felicidade".

A respeito da bissexualidade, o criador da psicanálise parece ter silenciado a seus leitores como o fizera com seus discípulos, por exemplo Ferenczi, "algumas poucas coisas pessoais...", apesar de ter escrito para Jung, que seu companheiro de viagem, cliente e discípulo, Ferenczi, tinha-se "comportado de maneira sumamente receptiva e passiva, deixando que se fizera tudo por ele, como uma mulher, e minha homossexualidade ainda assim não chega a aceitá-lo como tal (...)" Diz Freud (descrito assim em: Serge André - A impostura perversa, Jorge Zahar Editor, pp. 51-52, 1995).

Freud trata a bissexualidade na sua obra com o distanciamento de um "cientista", ao passo que Groddeck (outro contemporâneo), se apresenta bissexual. "Foi em 83 que me fizeram aquela observação de mau augúrio sobre o onanismo - diz George Groddeck, no Livro D'Isso, p. 189, Ed. Perspectiva, 1984 - logo depois peguei escarlatina e, quando me curei, fui tomado pela paixão por aquele colega com o qual passeava no pátio do convento e que eu beijava. (_) Eu falei dos desmaios do meu irmão prossegue - e eu os considero como tendo um papel particularmente importante no desenvolvimento da minha homossexualidade".

Por sua vez, Freud se irritava e acusava Groddeck de misticismo, apesar de posteriormente ter admitido que este "era um 'soberbo analista' que atincgia as camadas mais profundas do inconsciente-, carta a Groddeck em 1921.

Mesmo assim, Freud insistia nas bases químicas da sexualidade, embora aceitasse as sugestões de Fliess, quem também abordava o tema correlato da bissexualidade, sendo que Freud posteriormente iria considerar como um "fator decisivo", se bem que sua opinião final sobre a atuação desse fator o tenha colocado em desacordo com Fliess. Em 1897 Freud se viu forçado a abandonar sua teoria da sedução, simultaneamente com sua descoberta do Complexo de Édipo.

Chamou os bissexuais de "invertidos anfígenos" (ou hermafroditas sexuais), considerando que faltava o caráter de exclusividade na inversão ou levando em conta a ocasionalidade. 
Em 1906, W. Fliess reclamou para si a propriedade da idéia da bissexualidade (no sentido de dualidade do sexo), e mais tarde Freud se rendeu numa nota de rodapé (Três ensaios, pp. 134-135).

Freud escreve que "em matéria de sexualidade, somos todos, no momento, doentes ou sãos, não mais do que hipócritas. Será muito bom se obtivermos em conseqüência dessa franqueza geral, um certa dose de tolerância quanto às questões sexuais" (Obras completas, Vol. 3, 18931899).

Diz também "dos germes infantis da perversão, as zonas erógenas, e a predisposição para a bissexualidade" (Vol. VII, Três Ensaios sobre a se-vita lidade).

Faz correlação entre pares de opostos, sado-masoquismo, masculino-feminino, ativo-passivo, como combinações da bissexualidade... e acrescenta: "Em nenhuma pessoa sadia falta algum acréscimo ao alvo sexual normal que se possa chamar de perverso, e essa universalidade basta, por si só, para mostrar quão imprópria é a utilização reprobatória da palavra pervesão" (Três ensaios, $p$. 150).

Finalmente, no volume XXI, 1927-1931, sobre o futuro de uma ilusão, Freud que já havia escrito: "Desde que me familiarizei com a noção de bissexualidade, passei a considerá-la como o fator decisivo e penso que, sem levá-1a em conta, dificilmente se poderá chegar a uma compreensão das manifestações sexuais efetivamente no homem e na mulher. (...) A libido é masculina pois a pulsão é sempre ativa (...) cada pessoa exibe uma mescla de seus caracteres sexuais biológicos com os traços biológicos do sexo oposto. E ainda uma conjunção de atividade e passividade.- Agora, ele parece concluir: "O homem é um organismo animal com (como outros) uma disposição bissexual inequívoca".

Mas a psicologia, a despeito da anatomia que pode prová-la, não pode.

Tudo isto acontecendo na República de Weimar, com a liberação dos costumes alemães, num período pré-nazista.

Indicação de leitura: O Templo, Stephen Spender. Ed. Rocco, 1989, p. 105.

"Não importa o que dizem as letras em neon vermelho, mas a mancha de fogo que as reflete no asfalto".

Rua de mão única, Benjamin, 1928. 


\section{O ENIGMA BISSEXUAL: O CAMINHO DA SEXUALIDADE DO FUTURO}

"O agenciamento do conteúdo a de expressão não cai do céu - diz Félix Guattari, p. 41, O inconsciente maguinico: ensaios de esguizo-análise, Ed. Papirus, 1988.

O conteúdo e a expressão não são ligados um ao outro por virtude do Espírito Santo: no "início" dos agenciamentos de enunciação, não se encontram nem o verbo, nem o sujeito, nem o sistema, nem a sintaxe... mais: componentes de semiotização, de subjetivação, de conscientização, de diagramatismo e maquinismos abstratos.

Os sistema de correspondência e de tradução entre os estados da língua e os da cultura, tanto num plano sincrônico, não caminham por si mesmos?

Quando parecem participar do senso comum é porque são tratados de modo apropriado para responder a este fim. Todas as significações, todos os modos de semiotização, devem ser reportados a seus agenciamentos de enunciação. É destes que depende o grau de autonomia do plano de conteúdo sobre o qual se inscrevem a regulagem de seu ângulo de significação em relação às condições locais do triângulo semiológico, isto é, no fim das contas, sua capacidade semiótica de "ter na mão" um sub-conjunto dado do mundo mutável da representação e dos morfemas do referente, conservando sua própria coesão funcional no quadro das sintaxes dominantes. O Estatuto do Sujeito não repousa pois num jogo de significante, como quer a psicanálise estruturalista (...).

A separação entre o sujeito e o outro; a lei e o plano de conteúdo corresponde sempre ao de objetos particulares de poder. O conteúdo não cristaliza um mundo universal, mas uma mundaneidade marcada por campos de força contingentes, centrada em sistema bem precisos de ressonância subjetiva. As redundâncias fálicas, por exemplo, não dizem respeito a uma função simbólica universal, mas a poderes masculinos, instituições autoritárias, traços de aparência repressivos bem particularizados.

Numa matéria de capa publicada pela revista Istoé, em 18 de outubro de 1995, lê-se (...) "Nos Estados Unidos os que assumem sua bissexualidade se reúnem em movimentos com força e identidade próprias.

Praticamente todas as escolas e universidades americanas possuem agremiações de bissexuais, e os grupos desta orientação já somam 1.400 no mundo todo (...). 
"O verbo que eles usam para definir seu comportamento é 'transitar' (...) Não se trata de uma opção sexual solidificada, mas de uma espécie de abertura aritmética".

Diz também que no Brasil não há grupos assumidos por causa do estigma provocado pelo HIV ou por se tratar do "país do carnaval".

No entanto, "espera-se" que dentro de duas ou três décadas, a maioria das pessoas seja bissexual.

Nesta mesma matéria, Camille Páglia refere-se aos bissexuais como sendo: "orfãos de famílias desintegradas, mentalmente francos a culturalmente débeis". "Trata-se de uma regressão", acrescenta, mas preve para o próximo milênio, esse comportamento como norma universal, pois é um modismo - e a moda, segundo consta, pega.

Voltando a Freud, na sua famigerada "psicogênese de um caso de homossexualismo numa mulher" - Obras complelas, vol. XVIII, além do princípio do prazer, etc., 1920-22 - "O homossexualismo nas mulheres, que certamente não é menos comum que nos homens, embora muito menos manifesto, não só tem sido ignorado pela lei, mas também negligenciado pela pesquisa psicanalítica". Muitos psicanalistas pós-freudianos a até os atuais, continuam tentando, como Freud fizera, "remover a 'inversão genital' da mulher que não sentia nenhum conflito pela sua sexualidade per-se - e consideram, como o mestre considerava, um êxito ter facilitado a restauração das funções bissexuais plenas (?) de pessoas restritas ao homossexualismo".

Teríamos, conseqüentemente, de fazer o mesmo com o heterossexualismo? Pois se as "funções plenas" estão na bissexualidade... ora...

Se continuo a deixar fluir autores e pensamentos, à dispersão deste ensaio resultará infinita. Penso que é chegada a hora de propor algum tipo de recolhimento possível, neste tema tão controvertido, para que tenha lugar o debate (pois esse é o objetivo).

Estou convicto de que o desejo humano não pode ser nomeado a não ser através de significantes (construtos simbólicos sócio-culturais), para os quais tem se considerado a objetalidade - afinal, o nome é sempre para o outro da cultura ou para outro da fala.

Bissexual já é um destes nomes que agencia verbos, sujeitos e talvez sistema e sintaxes.

Se bem que minha postura clínica é anti-estruturalista, pois não vejo como um analista poderia "categorizar" os clientes que atende?... Por outro lado, me interesso pelo destino social destes clientes que se auto-denominam "bissexuais", pois pretendo ajudá-1os a adentrarem na

língua pela porta principal dos significante. Paradoxal? 
Acompanhei durante um ano um grupo (análise do grupo), composto por sete indivíduos que se auto-denominavam: bissexuais. E continuo acompanhando-os individualmente, após a dissolução do grupo.

Além, como já disse, de outros tantos que sempre atendi em sessões individuais.

E considero por ora como um êxito, o fato de tê-los visto libertar-se das -atuações" que os impulsionavam a uma sexualidade dita por eles, como "paralela", clandestina e freqüentemente, desprotegida frente ao risco de contaminação pelo vírus da AIDS. Pois assumir um sexo mais seguro, implicava em assumir muito mais do que isso.

Poucos destes, no entanto, conseguiram o salvoconduto da parcela heterossexual com que se relacionam, seja sexual ou afetivamente, mantendo ainda o paralelismo, hoje ampliado, à parcela de vínculos afetivos com outros bissexuais ou homossexuais. Identificados em parte, pelos laços a lugares discursivos. O lugar do oprimido, que o bissexual parece atribuir-se parcialmente.

Todavia, creio ter ouvido a mais ampla e variada gama de solicitações, que vão de Gays ou Lésbicas que ocultam sua "porção" heterossexual, pelo temor de represálias heterofóbicas, até outros ditos "heteros", pedindo ajuda para sentir "tesão" por indivíduos do mesmo sexo, pois após várias tentativas, haviam fracassado nesta empreitada.

Para concluir, creio importante recortar duas questões, a meu ver, fundamentais.

A- Na clínica psicanalítica não há bissexuais, como não há nenhuma outra categoria sexual. Na clínica há sujeitos desejantes, com suas especificidades discursivas, significantes da neo-língua.

B- No social há bissexuais, mas não há um discurso identificatório ou continente, que possa ser utilizado como ponto de referência cultural.

Por ora há uma cisão em paralelo, onde o semblante do sujeito adentra pela porta da frente e a "sombra" o faz pela dos fundos, de preferência no escuro, em ponta de pés e gozando da adrenalina do enganador.

O que sem dúvida e bastante divertido, mas pode custar um preço exorbitante.

Por não falarmos aqui em inibição, sintoma e angústia.

Ou. para falar nisso, e para encerrar, citarei dois exemplos da clínica, onde a abordagem visa a desalienar o sujeito, e deixo em aberto o discurso político, onde, entre todos, construiremos uma vida melhor. 


\section{O CASO DO HOMEM BISSEXUAL}

Baseando-se em Freud, vejo múltiplas identificações. Ruptura do Ego, por identificações separadas. Identificação primitiva, com o pai. Ambivalência: de um lado é igual, de outro, o odeia. Ele mostra que tem esse "pau duro" do pai, para ter a mãe. Mas também traz uma parte da mãe dentro de si. E Ego fica em parte identificado com o pai e em parte, com a mãe. De um lado é igual, de outro a odeia.

Uma porcentagem identificado com o homem, outra com a mulher.

Dupla identificação: Bissexualidade e ambivalência, pois o ideal do Ego cobra identificação exclusiva. E o Super-Ego cobra que seja igual a mãe e ao pai. (Freud dizia que o ato sexual sempre acontece entre quatro indivíduos. Dois homens e duas mulheres, intercalados).

No caso do meu cliente, ele quer ser amado, ficando numa posição passiva-amorosa. A angústia se dá quando aquele/a que o ama vá embora.

Ambivalência: de um lado a realização do Édipo e de outro, o repúdio. Está dividido, mas não como acredita em homo e hetero, e sim em amor - e ódio. Perante estas duas forças conflitantes parece ficar passivo.

Ao chegar a análise o amor é predominante. No percurso, o ódio começa a aumentar.

Ele procura relacionar-se com homens e mulheres, mas com homens o que importa é olhar. O olhar é que está sexualizado (pois o pai o olhava em sigilo). Ele transforma-se em "exibicionista" para esse pai "vouyeur". No entanto, não se permite demonstrar prazer com isso. Não pode achar graça nenhuma, pois apesar de gostar da sensação de estar sendo olhado pelo pai, não podia demonstrar pois estava com raiva dele. Digamos, excitava-se ao sentir olhado pelo pai, mas não podia mostrar pois estava com raiva pelo abandono. Assim, se comportava indiferente. Para evitar a humilhação,

Não pode aceitar que odeia, porque ama. Não pode aceitar que ama, porque odeia. A melhor solução é a indiferença. Além do que, o amor pelo pai, dasapontaria a mãe, também abandonada.

Esta é a prisão. Não a bissexualidade. Livre do ódio, provavelmente poderá amar: homens e mulheres, se quiser.

\section{O CASO DA MULHER BISSEXUAL}

A sexualidade dela vai mal. Com mulheres esta vinculada ao afeto com a mãe. Com homens, parece estar em função do narcisismo. 
Ela defende a idéia de que é o homem que deve trabalhar e sustentar a casa, coisa que o pai dela não fez, empurrando-a a este lugar. Queixa-se de pagar para ter afeto. Faz com as pessoas o que queria que o pai (ou a mãe) fizessem com ela. Pagar tem o sentido de dar afeto. Mas significa também o oposto. Se tem dinheiro não precisa do afeto dos pais. Logo a queixa é: falta de amor. Assim ela procura um analista que a ame. Me diz: "quero sua ajuda para gostar somente de homens". Eu ouço: "Quero ajuda para gostar somente do meu pai".

O curioso é que a vivência heteroerótica é uma vivência perversa, que lhe exige algum tipo de lei. Mas a única lei que encontra é abandonar o preservativo quando gosta do homem. Há um critério: gostar do homem. Mas um gostar extremamente sexualizado. Um afeto está ligado ao pai. Ligado ao gozo. Mas um gozo perigoso, sem lei. Outro afeto está ligado a mãe, afeto de carícias.

O conflito básico parece o da: liberalidade X juizo. Na falta de pai ela fica solta, sem limites. Precisa de um pai para colocar uma ordem. Mas tem que ser um pai que a ama.

Depois de uma infância dedicada ao pai, voltou-se para a mãe e tentou uma simbiose narcísica, mas era tarde. Os homens não lhe dão o que quer e as mulheres querem dinheiro.

As mulheres lhe roubam o tesão. Os homens a abandonam. De qualquer maneira está excluída (ou sente-se) desta família.

O juizo é a morte. A morte do desejo, a crítica tão temida. A vida é a liberalidade. Goza na liberalidade, mas não dá. Muito menos hoje em dia. Não dá para ficar engolindo esperma. Não dá para ficar engolindo emoções.

A ambos a mãe deu-lhes a vida (como a todos nós, é claro), mas depois lhes roubou. É uma mãe que dá e tira. A ambos, o pai abandonou-os (será, como a todos nós?).

Não conseguem estar bem em lugar nenhum, Ficam sempre procurando, mas não vão achar lá fora o que procuram. Pois procuram a existência deles. Procuram amor, mas quando encontram, ficam deprimidos.

Parece que estão buscando um pai e uma mãe razoáveis. Estão buscando um pouco de regra nessa loucura toda da família.

As mães querem nas duas pessoas: filhos e maridos. Desse jeito elas, as mães, não têm que lidar com suas próprias perdas. Obrigam os filhos a sofrer por elas.

E quem não gostaria de uma família melhor?

Como poderão ver, estas histórias em pouco diferem das histórias habituais de todas as pessoas. 
Os que buscam por ali, "causas" da bissexualidade, perdem seu tempo. De minha parte, busco por ali a libertação dos clientes da prisão que representa o "desejo do outro" (o desejo materno).

Com a convicção de que posteriormente poderão viver suas próprias vidas e construir (resignificar) suas próprias identidades.

Eu creio que este sim seja o "sexo do futuro", como proclama a Istoé, mas para todos nós.

Os sujeitos dos discursos, que nós auto-denominamos de "Eu" e cristalizamos a ação mediante um verbo: "sou"... Talvez um dia "Transitemos". "Transitar" é preciso? 